\title{
“PARANÁ FALA INGLÊS” NA UEPG: EXPERIÊNCIA EXTENSIONISTA COM FOCO NA MOBILIDADE INTERNACIONAL
}

\author{
Isabel Cristina Vollet Marson \\ Universidade Estadual de Ponta Grossa \\ isabel.marson@yahoo.com.br
}

Elaine Ferreira do Vale Borges Universidade Estadual de Ponta Grossa elainefvb@uol.com.br

\begin{abstract}
Resumo
O projeto "Paraná Fala Inglês" é uma proposta da SETI (Secretaria da Ciência, Tecnologia e Ensino Superior) junto às universidades estaduais do Paraná, para impulsionar a mobilidade internacional de alunos de graduação e pós-graduação, docentes e agentes universitários. O projeto iniciou-se em 2014, sendo a primeira etapa do programa da SETI “O Paraná Fala Línguas Estrangeiras". Sete universidades participam do programa: Universidade Estadual de Ponta Grossa (UEPG), Universidade Estadual de Londrina, Universidade Estadual de Maringá, Universidade Estadual do Norte do Paraná, Universidade Estadual do Paraná, Universidade Estadual do Oeste do Paraná e Universidade Estadual do Centro-Oeste do Paraná. Esse artigo apresenta os resultados parciais desse programa na UEPG sob a forma do curso de extensão, aprovado e registrado pela Pró-Reitoria de Extensão e Assuntos Culturais, "Paraná Fala Inglês - Curso preparatório intermediário e pós-intermediário do TOEFL-iBT". Ainda, objetiva-se discutir as perspectivas do projeto para sua finalização em 2016. Palavras-chave: Mobilidade internacional. Projeto Paraná Fala Inglês. TOEFL iBT.
\end{abstract}

\section{"PARANÁ SPEAKS ENGLISH" AT THE UEPG: EXTENSION EXPERIENCE WITH FOCUS ON INTERNATIONAL MOBILITY}

\begin{abstract}
The "Paraná Speaks English" is a SETI (Secretaria da Ciência, Tecnologia e Ensino Superior) project proposal for the state universities of Paraná. The SETI goal is to improve the international mobility of graduate and postgraduate students, teachers and university staff. The project began in 2014 and it is the SETI program first stage "The Paraná Speaks Foreign Languages". Seven universities participate in the program: Universidade Estadual de Ponta Grossa (UEPG), Universidade Estadual de Londrina, Universidade Estadual de Maringá, Universidade Estadual do Norte do Paraná, Universidade Estadual do Paraná, Universidade Estadual do Oeste do Paraná, and Universidade Estadual do Centro-Oeste do Paraná. This article presents the partial results of this program at the UEPG, which was stablished by an extension course "Paraná Fala Inglês - Curso preparatório intermediário e pós-intermediário TOEFL-iBT", approved and registered by the PróReitoria Extensão e Assuntos Culturais. The objective is also to discuss the project prospects and its completion in 2016. Keywords: International mobility. Paraná Speaks English Project. TOEFL iBT.
\end{abstract}

\section{"PARANÁ HABLA INGLÉS" EN LA UEPG: EXPERIENCIA}

\section{EXTENSIÓNISTA CON EL FOCO EN MOVILIDAD INTERNACIONAL}

\section{Resumen}

El "Paraná habla Inglés" es una propuesta de SETI (Secretaría de Ciencia, Tecnología y Educación Superior) con las universidades estaduales de Paraná, para impulsar la movilidad internacional de los estudiantes de graduación y postgrado, profesores y agentes universitarios. El proyecto comenzó en 2014, la primera etapa del programa SETI es El Paraná Habla Idiomas Extranjeros. Hay siete universidades participantes del programa: Universidade Estadual de Ponta Grossa (UEPG), Universidade Estadual de Londrina, Universidade Estadual de Maringá, Universidade Estadual do Norte do Paraná, 
Universidade Estadual do Paraná, Universidade Estadual do Oeste do Paraná y Universidade Estadual do Centro-Oeste do Paraná. Este artículo presenta los resultados parciales de este programa en la UEPG en forma de curso de extensión, aprobado y registrado por el Decano de Extensión y Asuntos Culturales, "Paraná Habla Inglés - Curso Preparatorio intermedio y pos-intermedio-iBT TOEFL". Además, tenemos el objetivo de discutir las perspectivas del proyecto para su finalización en 2016.

Palabras clave: La movilidad internacional. Proyecto Paraná Habla Inglés. TOEFL iBT. 


\section{INTRODUÇÃO}

A mobilidade internacional é atualmente um tema importante nos espaços acadêmicos e uma preocupação de governos estadual e federal brasileiro. Isso se deve ao crescente fluxo de estudantes e professores interessados em frequentar universidades e programas de pós-graduação no exterior, bem como à necessidade de capacitar as futuras gerações para que possam trocar experiências, transpor barreiras, promover transformações na sociedade brasileira e promover a inclusão social e cultural. Por essa perspectiva, a internacionalização pode ampliar os horizontes da educação superior, tornando-a global, acessível. No entanto, é fundamental analisar criticamente o conceito de internacionalização para não se deixar cair na falácia da promoção da internacionalização do ensino superior como um fim em si mesmo, como uma mercadoria a ser negociada. Brandenburg e De Wit (2011, p. 17), por exemplo, ressaltam que “[...] o que nós precisamos são pessoas que compreendam e definam seus papéis numa comunidade global, transcendendo as fronteiras nacionais e abraçando os conceitos de sustentabilidade - equidade de direitos e acesso, avanço da educação e pesquisa ${ }^{1 \%}$.

De acordo com Nogueira (2006), são visíveis os benefícios para os acadêmicos que já tiveram oportunidade de passar um tempo fora do país, uma vez que tal experiência propicia a assimilação mais ampla do contexto cultural e os alunos, na maioria das vezes, conseguem desenvolver com excelência a língua estrangeira. Ainda, é importante que, nesse processo de internacionalização, os candidatos tenham desenvolvimento pessoal, formação acadêmicoprofissional e proficiência linguístico-comunicativa na língua estrangeira para conseguir uma pontuação mínima exigida em testes internacionais requeridos pelas universidades estrangeiras e setores privados.

Para essa demanda que se apresenta, as universidades brasileiras, junto aos governos estaduais e federal, voltam-se para a capacitação em línguas estrangeiras de candidatos à mobilidade internacional, movidas, principalmente, pelo surgimento de programas federais como o Idiomas Sem Fronteiras do Ministério da Educação (MEC). Espera-se com isso promover o desenvolvimento de habilidades extremamente valorizadas no tempo atual, como domínio de uma língua estrangeira, conhecimento da cultura de outros povos, capacidade de adaptação às mudanças, flexibilidade e abertura a novas maneiras de aprender (VIEIRA, 2007 apud RAMOS, 2009).

\footnotetext{
${ }^{1}[\ldots]$ what we need are people who understand and define their role within a global community, transcending the national borders, and embracing the concepts of sustainability - equity of rights and access, advancement of education and research. (Tradução de responsabilidade dos autores)
} 
Dessa forma, iniciativas propostas pelo governo federal sinalizam o reconhecimento da necessidade de desenvolvimento científico que transpasse os limites fronteiriços do nosso país, sendo fundamental encorajar professores, acadêmicos, pós-graduandos e agentes universitários para a internacionalização, o que possibilita o estabelecimento de parcerias frutíferas com centros de pesquisas renomados e a revisão dos procedimentos de pesquisa internos utilizados nas nossas instituições nacionais (SCIENCE WITHOUT BORDERS, 2011). O programa de mobilidade internacional Ciência sem Fronteiras é uma dessas iniciativas. Este programa federal tem o objetivo de promover, consolidar e expandir a Ciência, Tecnologia e Inovação através do intercâmbio internacional, colocando os estudantes universitários brasileiros em contato com um meio de alta competitividade e empreendedorismo (SCIENCE WITHOUT BORDERS, 2011). Porém, não basta estar frequentando um curso de graduação para ingressar no programa, já que há critérios para a candidatura de acadêmicos, incluindo um determinado nível no desempenho escolar, o rendimento satisfatório na universidade e principalmente a proficiência na língua estrangeira utilizada pela instituição para a qual eles se candidataram. (NOGUEIRA et al 2008).

Por outro lado, o estado do Paraná, por iniciativa da SETI (Secretaria da Ciência, Tecnologia e Ensino Superior), lança o programa O Paraná Fala Linguas Estrangeiras e seu primeiro projeto é denominado Paraná Fala Inglês (PFI). Este projeto é pioneiro no estado paranaense e visa atender a demanda da mobilidade internacional das universidades estaduais que não são diretamente contempladas pelo programa federal Idioma sem Fronteiras e Inglês sem Fronteiras (IsF) do MEC/SESu², uma vez que a SESu é uma unidade do MEC voltada essencialmente à manutenção, supervisão e desenvolvimento das instituições públicas federais. O programa $O$ Paraná Fala Linguas Estrangeiras visa desenvolver projetos que possam contribuir para a melhoria da competência linguístico-comunicativa em várias línguas estrangeiras para a internacionalização das universidades paranaenses. Um dos objetivos desses projetos é ofertar cursos preparatórios para exames internacionais de proficiências em língua estrangeira para alunos de graduação e pósgraduação (mestrado e doutorado), docentes e agentes acadêmicos das universidades participantes do projeto. Sete universidades paranaenses participam do programa: UEPG (Universidades Estadual de Ponta Grossa), UEL (Universidade Estadual de Londrina), UEM (Universidade Estadual de Maringá), UENP (Universidade Estadual do Norte do Paraná), UNESPAR (Universidade Estadual do Paraná), UNIOESTE (Universidade Estadual do Oeste do Paraná) e UNICENTRO (Universidade Estadual do Centro-Oeste do Paraná).

\footnotetext{
2 Ministério da Educação/ Secretaria de Ensino Superior.
} 
“Paraná fala inglês" na UEPG: experiência extensionista com foco na mobilidade internacional

Este artigo propõe-se a apresentar os principais resultados do projeto Paraná Fala Inglês na UEPG, no período de 2014 até o início de 2015, e o planejamento das atividades subsequentes para a sua finalização em 2016.

\section{MATERIAIS E MÉTODOS}

\section{Desdobramentos e etapas do projeto Paraná Fala Inglês (PFI) na UEPG}

O Paraná Fala Inglês (PFI) na UEPG, vinculado ao programa Paraná Fala Lingua Estrangeiras, é um projeto de iniciativa da SETI com recursos financeiros do Fundo Paraná. No primeiro semestre de 2013, depois de várias negociações entre a SETI e as universidades estaduais paranaenses, o projeto então nomeado O Paraná Fala Linguas Estrangeiras - Primeira Etapa - O Paraná Fala Inglês (PARANÁ FALA INGLÊS, 2013) surgiu em cada instituição de ensino superior (IES) do Paraná, com características, metas e objetivos similares, porém visando a atender às peculiaridades de cada IES.

Assim, para a estruturação e proposta concreta do projeto a ser desenvolvido nas universidades, foram realizadas reuniões com a coordenadora de Ciência e Tecnologia da SETI e todos os coordenadores dos projetos nas universidades. A proposta buscou seguir, na medida do possível (visto que cada universidade tem suas especificidades), um mesmo padrão de desenvolvimento e cronograma de ações nas sete universidades estaduais participantes, tendo sido dividido o projeto em três etapas e com a duração total de 22 meses. Cada universidade pôde optar por uma coordenação institucional e outra pedagógica e/ou uma coordenação geral e um(a) aluno(a) de graduação (como bolsista) para ajudar na parte administrativa. O projeto da UEPG optou por uma coordenação institucional e outra pedagógica.

De forma geral, o objetivo do projeto em cada IES é capacitar estudantes (graduação e pós-graduação), docentes (das áreas tecnológicas e humanas) e agentes universitários, preferencialmente das instituições de origem, mas também de outras universidades dos municípios dos Campos Gerais, que façam parte do Programa da SETI, visando à internacionalização das universidades estaduais. Os objetivos específicos focam na elaboração e oferta de cursos preparatórios (intermediário e pós-intermediário) do TOEFL iBT (Test of English as a Foreign Language - Internet Based Test), de 120 horas cada, com 150 vagas, a fim de preparar os candidatos para, ao final dos cursos, prestarem o exame TOEFL-iBT. 
O Projeto da UEPG, redigido em formulário próprio da SETI, foi assinado pelo Reitor em maio de 2013. Todavia, no final de 2013, novas discussões entre a SETI e as universidades estaduais paranaenses foram necessárias e ficou decidido que os projetos de todas as IES seriam executados a partir de 2014, divididos em 3 etapas, assim distribuídas:

$\checkmark$ Primeira etapa: 90 vagas para o curso preparatório intermediário do TOEFL-iBT e 30 para o pós-intermediário;

$\checkmark$ Segunda etapa: 90 vagas para o curso pós-intermediário do TOEFL-iBT (visando aos alunos que completarem o curso intermediário da primeira etapa);

$\checkmark$ Terceira etapa: 30 vagas para o curso pós-intermediário do TOEFL-iBT e 30 para o pósintermediário (visando aos alunos que completarem o curso intermediário da terceira etapa);

Nesse panorama, os cursos iniciaram efetivamente em julho de 2014, após a liberação do orçamento pela SETI, porém, a primeira etapa já teve início em maio - com o lançamento de editais de inscrição dos candidatos e a aplicação de testes de nivelamento para a distribuição das vagas - e término em dezembro de 2014. A segunda etapa iniciou em janeiro de 2015 e está prevista para terminar em agosto de 2015. A terceira e última etapa terá início em agosto de 2015 e prevê cursos e turmas até fevereiro de 2016. O projeto tramita na UEPG por meio do Curso de Extensão Paraná Fala Inglês - Curso preparatório intermediário e pós-intermediário do TOEFL-iBT, aprovado pela Pró-Reitoria de Extensão (PROEX) da instituição.

Para a inserção dos candidatos nas 150 vagas ofertadas - distribuídas ao longo das etapas do projeto entre os cursos preparatórios intermediário e pós-intermediário - foi aplicado o teste de nivelamento TOEFL ITP (Test of English as a Foreign Language - Institutional Testing Program) - Nível 1 (intermediário a avançado). Os testes foram disponibilizados às IES, já na primeira etapa do projeto, pela SETI (300 para cada universidade), os quais, após aplicados, são corrigidos pela empresa Mastertest Certificação Internacional (representante exclusiva no Brasil dos testes TOEIC e TOEFL ITP). Os cursos do projeto são gratuitos e exclusivamente ofertados para alunos de graduação, mestrado e doutorado, docentes e agentes universitários das instituições que participam do projeto da SETI, mas todo o material didático, incluindo os livros didáticos adotados (PHILLIPS, 2009 e 2013), deve ser adquirido com recursos próprios de cada candidato (situação prevista no edital de inscrição para os cursos).

A coordenação do projeto, em parceria com a pró-reitoria de extensão da UEPG, considera fundamental a implementação de projetos como os do programa Paraná Fala Linguas Estrangeiras da SETI para o desenvolvimento da internacionalização das universidades paranaenses. Na concepção de Scortegagna (2013), é fundamental promover o desenvolvimento 
da língua inglesa no país para ampliar a ciência. Na concepção do autor, a internacionalização das universidades brasileiras tem mobilizado a comunidade acadêmica e estendido os horizontes das pessoas que participam dos projetos.

\section{Primeira etapa: iniciando as atividades e entendendo o processo na prática}

Na UEPG, como já enfatizado, a primeira etapa do projeto Paraná Fala Inglês (PFI) aconteceu de maio a dezembro de 2014, tendo os cursos sido iniciados em julho. Primeiramente, foi feita a seleção e contratação de quatro professores instrutores para lecionar nos cursos propostos pelo projeto: dois internos da instituição para os cursos pós-intermediários e dois externos para os cursos intermediários. Os professores externos foram selecionados em teste seletivo com chamada via edital interno da instituição, em abril de 2014. Cada professor ficou responsável por duas turmas de 15 alunos cada, totalizando 120 vagas nessa primeira etapa (as 30 vagas restantes seriam preenchidas em etapas posteriores, com novas turmas de pósintermediário).

Após a seleção dos professores, houve capacitação ${ }^{3}$ (em maio de 2014) de toda a equipe do projeto (coordenadoras e professores), com duração de 8 horas. Em seguida, um edital de inscrições de candidatos aos cursos foi lançado, no qual podiam se inscrever alunos (graduação, mestrado e doutorado), professores e agentes universitários que comprovassem vínculo com a UEPG e/ou com as universidades participantes do programa da SETI. Após a comprovação do vínculo com as IES participantes do projeto, através da verificação dos documentos comprobatórios pela coordenação, foi aplicado o teste de nivelamento TOEFL ITP - Nível 1 (intermediário a avançado) aos 232 inscritos para o preenchimento das 150 vagas disponíveis. Os testes foram corrigidos pela Mastertest e os resultados publicados em edital interno da UEPG, no dia 25 de junho.

De acordo com os resultados nos testes de nivelamento (score), os candidatos foram distribuídos nos dois cursos ofertados (Curso 1 - pré-preparatório, nível intermediário do TOEFL iBT e Curso 2 - preparatório, nível pós-intermediário do TOEFL iBT). A equivalência das notas (scores) dos testes de nivelamento TOEFL ITP, para a distribuição dos candidatos nos cursos, foram baseadas no Quadro Europeu Comum de Referência para as Línguas Estrangeiras (QERC) (CONSELHO DA EUROPA, 2001), conforme Quadro 1:

\footnotetext{
3 A capacitação de professores foi realizada na Universidade Estadual de Londrina, no dia 30/05/2014, com duração de 8 h e emissão de certificado.
} 


\begin{tabular}{|c|c|c|}
\hline PFI & $\begin{array}{c}\text { Curso Preparatório } \\
\text { Intermediário }\end{array}$ & $\begin{array}{c}\text { Curso Preparatório } \\
\text { Pós-intermediário }\end{array}$ \\
\hline QECR & Nível A2 - Pré-Intermediário & Nível B2 - Intermediário \\
\hline Score TOEFL ITP & $337-459$ & $460-542$ \\
\hline
\end{tabular}

Quadro 1 - Primeiro quadro de equivalência QERC e TOEFL ITP

Fonte: Elaborado pelos autores, tendo como referência as notas do QERC e do TOEFL ITP

Os Cursos 1 e 2 tiveram início em 21 de julho e término em 17 de dezembro de 2014, sendo que cada um dos quatros professores instrutores ficou responsável por 2 turmas de 15 alunos: o Curso 1, com aulas às segundas e quartas-feiras, das 13:00 às 17:00h, e o Curso 2, com aulas aos sábados (no período da manhã e tarde, das 8 às $12 \mathrm{~h}$ e das 13 às $17 \mathrm{~h}$ ) e às segundas e quintas-feiras, das 9:30 às 11:30h.

No planejamento inicial do projeto, estavam previstos 90 alunos para o Curso 1 (6 turmas) e 30 alunos para o Curso 2 (2 turmas); porém, devido ao score mais alto dos candidatos no teste de nivelamento, foram ofertadas 60 vagas para o curso 1 e 60 vagas para o curso 2. O Quadro 2 abaixo mostra a divisão de score das turmas.

\begin{tabular}{|c|c|c|}
\hline PFI & $\begin{array}{c}\text { Curso Preparatório } \\
\text { Intermediário }\end{array}$ & $\begin{array}{c}\text { Curso Preparatório } \\
\text { Pós-intermediário }\end{array}$ \\
\hline QECR & Nível A2 - Pré-Intermediário & Nível B2 - Intermediário \\
\hline Score TOEFL ITP & $380-467$ & $470-637$ \\
\hline
\end{tabular}

Fonte: Elaborado pelos autores, tendo como referência as notas do QERC e do TOEFL ITP

Considerando que os testes de nivelamento apresentaram scores maiores em relação à previsão inicialmente feita pela coordenação, optou-se por ofertar 4 turmas para os candidatos com score entre 637-470 (pós-intermediário) e 4 turmas para os candidatos com score entre 380-467 (intermediário), aproveitando-se, assim, o maior número de candidatos possíveis nas turmas. No entanto, devido às poucas opções de horário dos quatro professores para ministrarem os cursos, alguns problemas de adaptação, por parte dos alunos, nos horários propostos, foram detectados. Como o projeto recebia alunos, professores e agentes universitários numa mesma turma, muitos deles não puderam se adaptar aos horários propostos, que foram organizados por ordem de score (nota) e pelos horários disponibilizados pelos professores instrutores. Inicialmente havia 15 participantes por turma, porém, no decorrer das aulas, esse número foi diminuindo e, por esse 
motivo, um novo edital foi lançado para a chamada dos alunos em lista de espera na tentativa do preenchimento das vagas referentes às desistências.

Como cada curso tem uma carga horária total de 120 horas no semestre, elas foram subdivididas em 88 horas presenciais (4 horas semanais presenciais) e 32 horas à distância. Estas últimas foram desenvolvidas, de modo concomitante às aulas presenciais, no ambiente virtual de aprendizagem Moodle, disponibilizado pelo NUTEAD (Núcleo de Tecnologia e Educação Aberta e a Distância) da UEPG, com exemplos de atividades contidas nas Figuras 1 e 2.

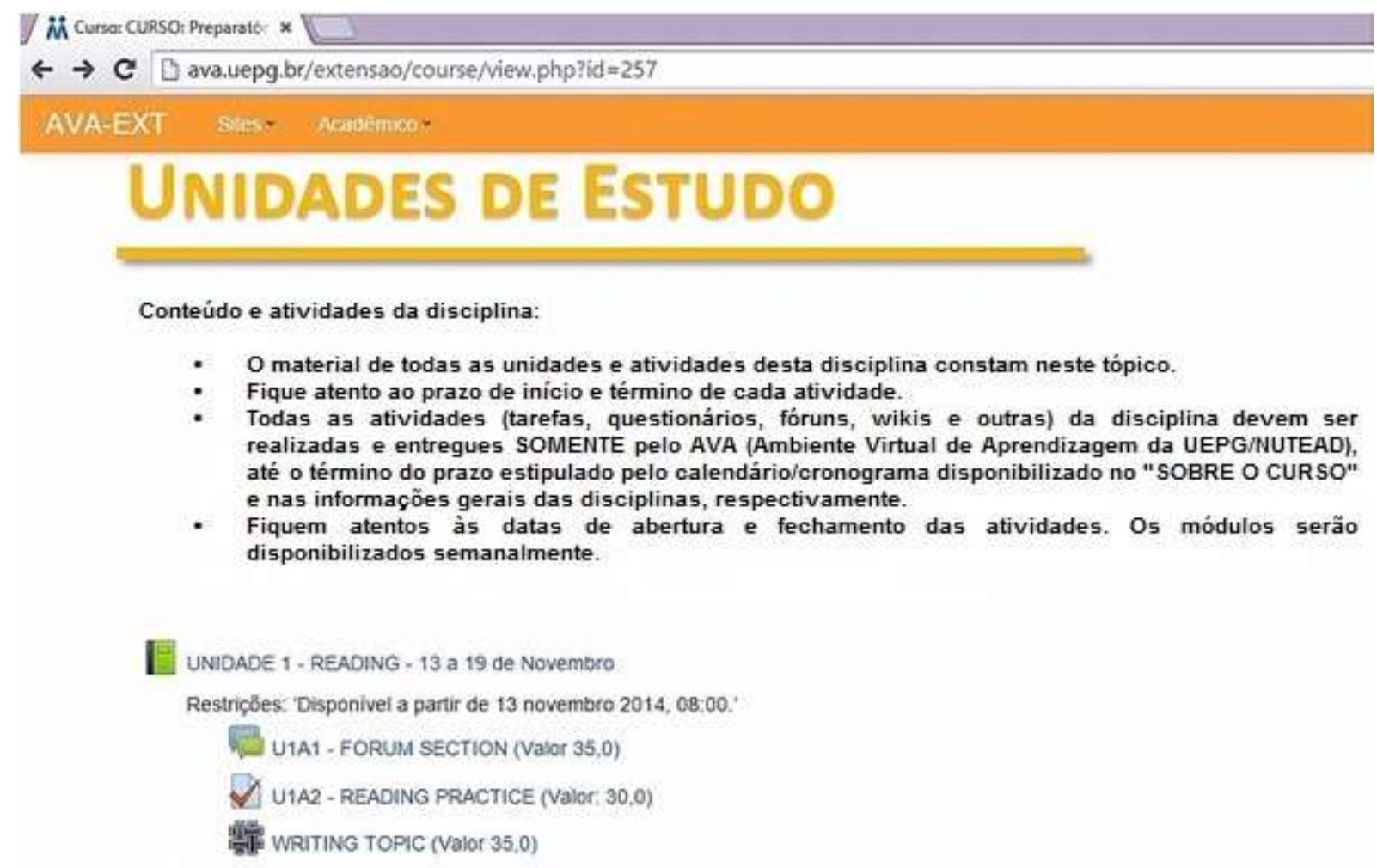

Figura 1 - Imagem do Ambiente Virtual de Aprendizagem utilizado pelos participantes do curso Preparatório do TOEFL iBT - 32 horas a distância

Fonte: Universidade Estadual de Ponta Grossa. Moodle - Ambiente Virtual de Aprendizagem (AVA-UEPG), NUTEAD, Ponta Grossa, 2014.

No planejamento inicial do projeto (em conjunto com todas as IES), o material didático (PHILLIPS, 2009 e 2013) utilizado nos cursos deveria ser cumprido em seis meses, porém, com o andamento das turmas e o rendimento dos alunos, verificou-se que o curso deveria ser feito em um ano. Assim, a equipe pedagógica da UEPG analisou o material didático e a divisão de tempo proposta para o cumprimento das 120 horas dos cursos e percebeu que esse tempo poderia ser dividido em duas ou três sessões. Como os cursos tinham a carga horária de quatro horas 
semanais presenciais, decidiu-se por utilizar o material em duas sessões com algumas turmas, como já era a proposta da autora do material didático adotado (PHILLIPS, 2009 e 2013). Dessa forma, todas as turmas tiveram 88 horas presenciais (cumprindo exclusivamente o livro didático) e 32 horas de atividades à distância (atividades complementares não incluídas no material didático). Com isso, dois planejamentos foram feitos concomitantes: um para utilizar o material didático em seis meses, em que duas turmas se formaram; e outro para utilização do material didático em um ano para seis turmas, remodelando a proposta inicial de ofertar apenas cursos semestrais.

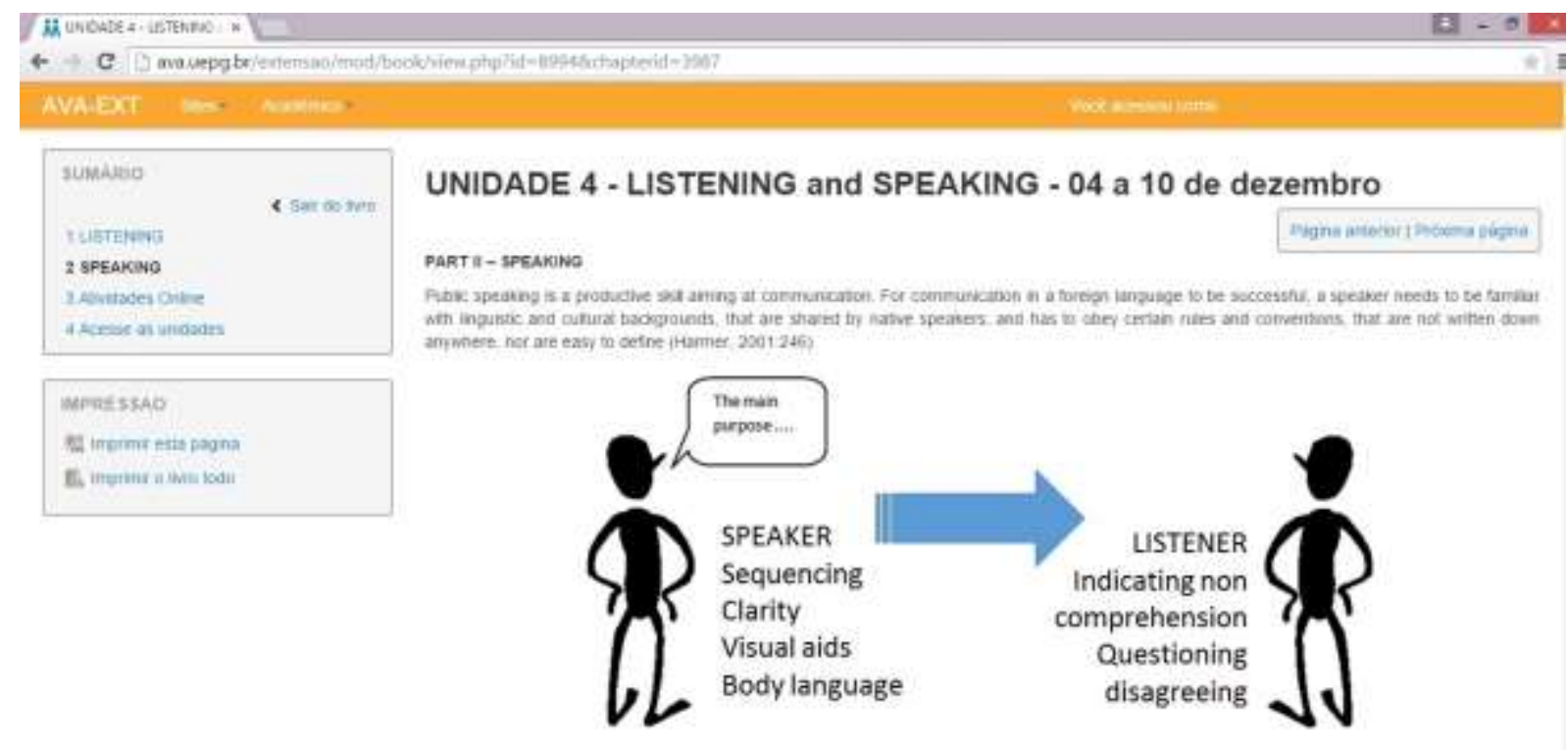

Figura 2 - Imagem do ambiente virtual de aprendizagem do Curso Preparatório do TOEFL iBT,

32 horas a distância - referente às práticas das habilidades de Listening e Speaking.

Fonte: Universidade Estadual de Ponta Grossa. Moodle - Ambiente Virtual de

Aprendizagem (AVA-UEPG), NUTEAD, Ponta Grossa, 2014.

Para completar os cursos, os participantes tiveram quatro provas no semestre, nas quais foram avaliadas as quatro habilidades da língua inglesa (Reading, Listening, Speaking Writing) trabalhadas no livro didático (PHILLIPS, 2009 e 2013) proposto em cada curso. Exigiu-se nota mínima em cada prova e 75\% de frequência em cada modalidade: presencial e a distância.

\section{Segunda etapa: remodelamento dos cursos}

Na segunda etapa do projeto PFI na UEPG, que iniciou no primeiro semestre de 2015, a coordenação lançou o edital de inscrição para novos candidatos em fevereiro, na tentativa de 
formar novas turmas nos cursos. As inscrições foram do dia 9 a 19 de fevereiro e as provas de nivelamento (TOEFL ITP - Nível 1) foram aplicadas no dia 24. A correção foi feita pela Masterest e um novo edital, em março, foi lançado para a chamada de início dos cursos. Nessa etapa, foi ofertada a aplicação de 146 testes de nivelamento TOEFL ITP, mas só 89 candidatos foram aprovados e distribuídos nas turmas novas, conforme segue abaixo:

$\checkmark$ Curso 1 - pré-preparatório (nível intermediário) do TOEFL iBT - duas turmas novas de 15 alunos cada, ofertado às segundas e quartas-feiras, das $13 \mathrm{~h}$ às $15 \mathrm{~h}$ e das $15 \mathrm{~h}$ às $17 \mathrm{~h}$.

$\checkmark$ Curso 1 - pré-preparatório (nível intermediário) do TOEFL iBT - duas turmas em andamento - continuação das unidades trabalhadas no ano passado (curso anual), ofertado às segundas e quartas-feiras, das $13 \mathrm{~h}$ às $15 \mathrm{~h}$ e das $15 \mathrm{~h}$ às $17 \mathrm{~h}$.

$\checkmark$ Curso 2 - preparatório (nível pós-intermediário) do TOEFL iBT - três turmas novas de 15 alunos cada, ofertado às segundas e quintas-feiras, das 9h30min às $11 \mathrm{~h} 30 \mathrm{~min}$ e das $19 \mathrm{~h}$ às $21 \mathrm{~h}$.

$\checkmark$ Curso 2 - preparatório (nível pós-intermediário) do TOEFL iBT - uma turma em andamento - continuação das unidades trabalhadas no ano passado (curso anual), ofertado aos sábados das $8 \mathrm{~h}$ às $11 \mathrm{~h}$.

\section{Terceira etapa: projeções para a finalização do projeto}

A terceira etapa do projeto PFI da UEPG está prevista para iniciar em agosto e finalizar em fevereiro de 2016. Prevê-se a oferta de duas turmas novas de 15 alunos cada uma, do nível pós-intermediário. A duração dos cursos está prevista para 6 meses, com início em agosto e término em dezembro de 2015. O professor que ministrará os cursos para essas turmas será da instituição, tendo em vista o término do contrato dos professores externos no primeiro semestre de 2015. Como todos os outros cursos, haverá atividades à distância (32h) e avaliações referentes a todas as habilidades em língua inglesa (Reading, Writing, Listening e Speaking).

$\mathrm{Na}$ conclusão dessa etapa, e para a concretização do término do projeto junto à instituição, à PROEX/UEPG e à SETI, será elaborado um relatório final, previsto para ser redigido e entregue às instâncias pertinentes, até o fim do mês de fevereiro de 2016. 


\section{RESULTADOS E ANÁLISES}

\section{Resultados parciais do Projeto PFI da UEPG}

O projeto Paraná Fala Inglês visa essencialmente atender à comunidade da UEPG de forma ampla e democrática, tendo em vista que podem participar dos cursos preparatórios alunos da graduação e pós-graduação (mestrado e doutorado), docentes e agentes universitários. No entanto, o projeto é limitado na oferta de vagas e não dá conta de suprir a necessidade latente de propostas de cursos que reforcem a proficiência da língua inglesa no uso das quatro habilidades (ler, ouvir, falar e escrever). Seria necessário que projetos como esse pudessem ter continuidade, transformando-se em programas dentro das instituições.

Entretanto, apesar de todas as dificuldades na implementação desse projeto pioneiro na UEPG e no Estado do Paraná, foi possível oferecer oportunidades de aprendizagem da língua inglesa em diversos níveis de proficiência. Foi possível, ainda, trabalhar todas as habilidades da língua (ler, ouvir, falar e escrever) de forma integrada, reforçando aquelas em que os alunos tinham mais dificuldade.

Estatisticamente, dos 120 candidatos que se inscreveram no mês de julho de 2014, primeira etapa do projeto, 49 participantes finalizaram, ou seja, 40,83\% (conforme Gráfico 1).

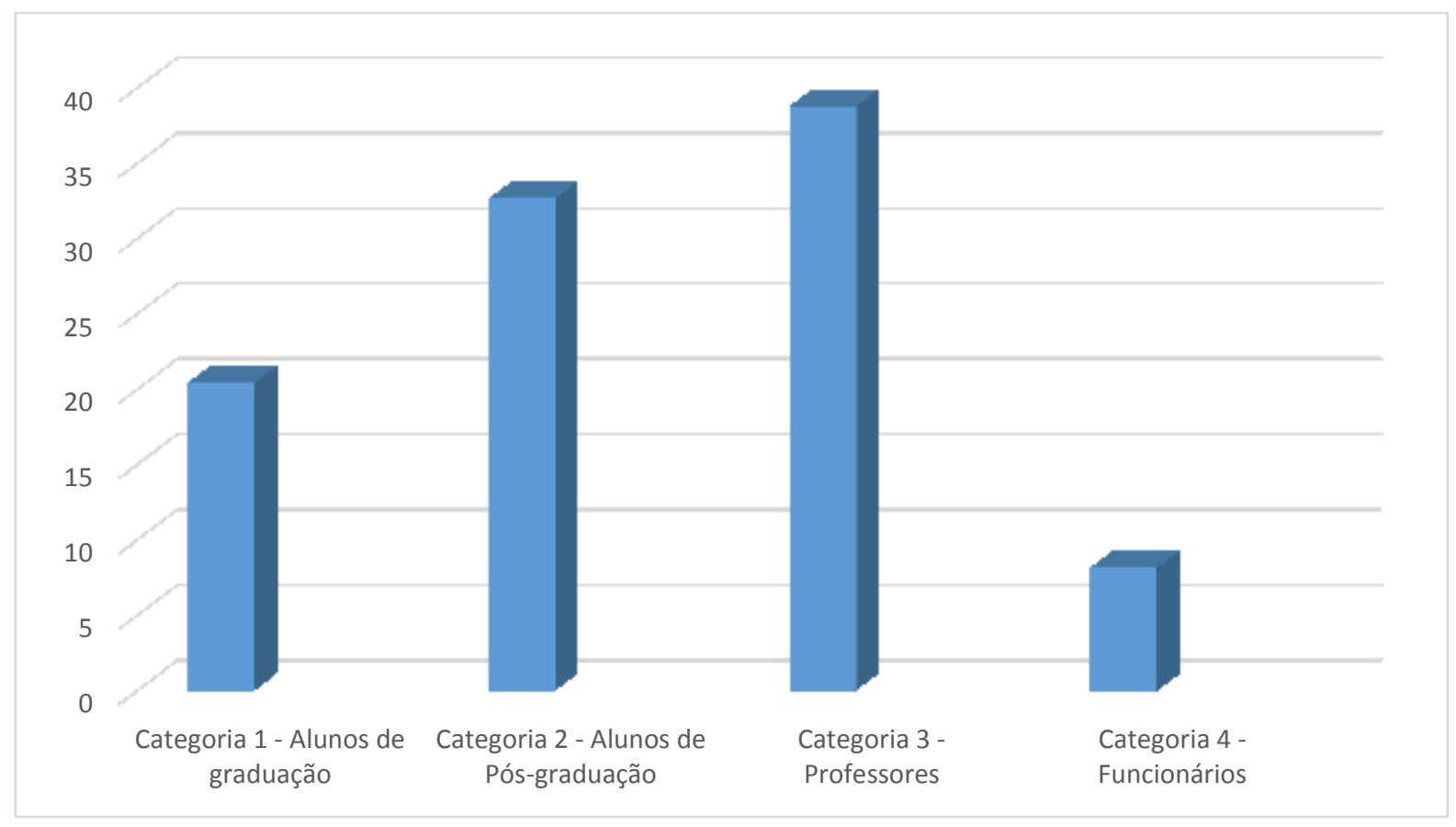

Gráfico 1 - Concluintes dos cursos 1 e 2 da Etapa 1 do PFI da UEPG 2014

Fonte: Elaborado pelos autores, 2015. 
Desses 49 concluintes, 10 eram oriundos da graduação $(20,41 \%), 16$ da pós-graduação (32,65\%), 19 eram professores da instituição (38,77\%) e apenas 4 eram funcionários $(8,16 \%)$. Percebe-se que, apesar de o projeto ter possibilitado oportunidades iguais de inscrição a alunos (graduação, mestrado e doutorado), professores e funcionários (agentes universitários), foram os docentes que mais aproveitaram a oferta de cursos propostos pelo projeto. Além do crescimento pessoal e do desenvolvimento da competência linguístico-comunicativa, elementos essenciais ao exercício da docência, os professores aproveitaram a oportunidade da formação continuada dentro dos muros da universidade, inseridos no contexto da mobilidade internacional. Outra categoria que participou com número expressivo no projeto foi a dos alunos de pós-graduação (com aumento da participação na etapa 2 - Gráfico 2), tendo em vista que já vislumbram possibilidades de cursar parte de suas pós-graduações (mestrado e doutorado) em instituições renomadas no exterior. O conhecimento da língua estrangeira permite aos estudantes de pós especializarem-se e socializarem-se em polos de pesquisa altamente qualificados, podendo conhecer e comparar sua realidade com a de outras culturas.

$\mathrm{Na}$ etapa 2, ainda em andamento, também foi verificado o perfil dos candidatos que frequentam os cursos do PFI até o mês de abril de 2015. Em duas semanas de curso, percebeu-se que a porcentagem de participantes dos cursos varia, conforme o Gráfico 2 abaixo. Diferentemente do Gráfico 1, a maior porcentagem de candidatos que estão frequentando os cursos, nessa segunda etapa (a partir de março de 2015), são alunos de pós-graduação (42,86\%). A segunda categoria mais marcante são alunos de graduação (38,78\%), e, em terceiro lugar, estão os professores $(12,24 \%)$; por fim, há uma parcela bem pequena de funcionários $(6,12 \%)$.

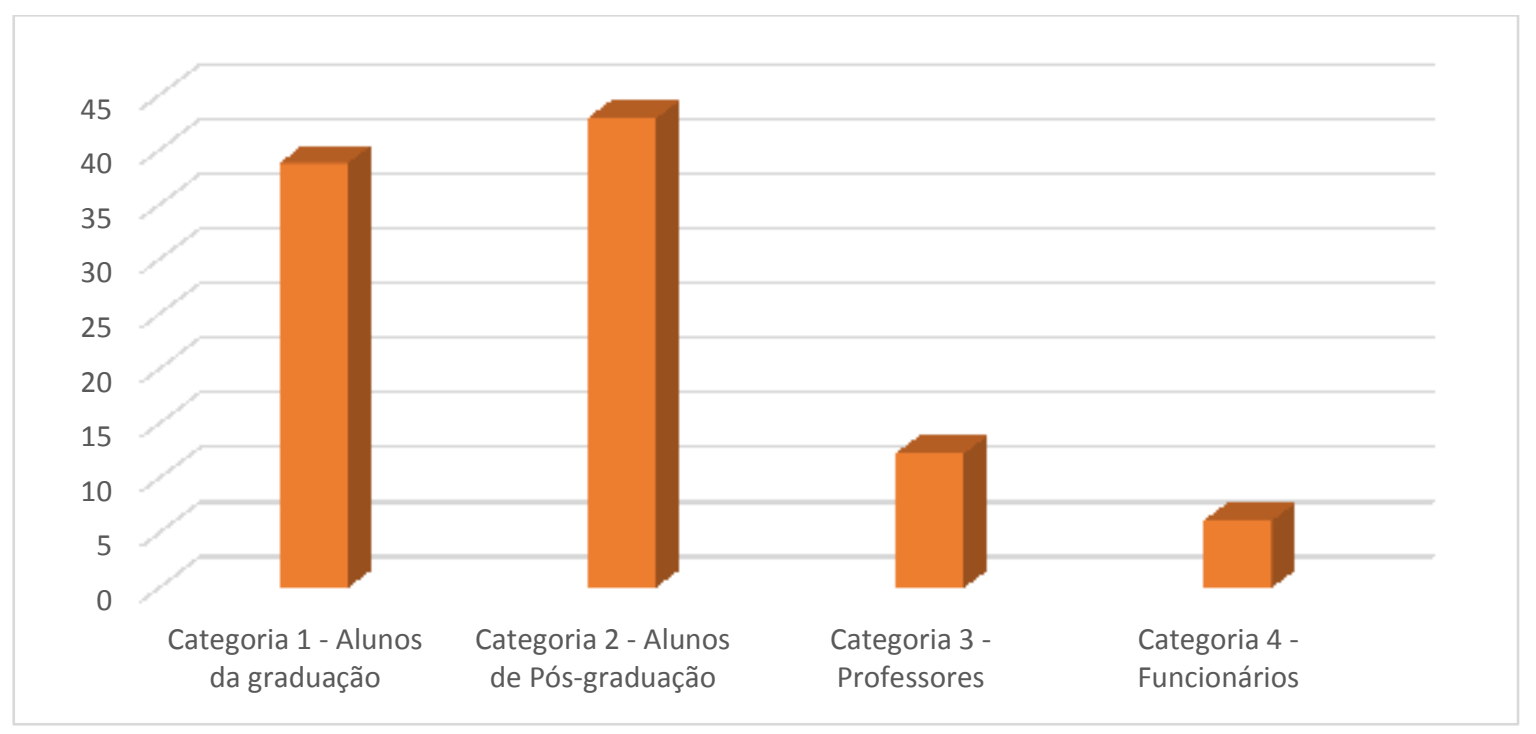

Gráfico 2 - Perfil dos candidatos na segunda etapa dos cursos do PFI da UEPG 2015

Fonte: Elaborado pelos autores, 2015. 
Percebe-se, também (nos Gráficos 1 e 2), uma demanda crescente de alunos da graduação procurando cursos e oportunidades que possibilitem a mobilidade internacional; isto em grande parte se deve às oportunidades geradas pelo programa federal Inglês Sem Fronteiras. Dessa forma, é fundamental que as universidades ofertem cursos e programas que permitam a proficiência da língua estrangeira, para transpor fronteiras e expor os alunos a novas culturas.

Além da reflexão sobre dados quantitativos, a coordenação pode avaliar e compreender, com a aplicação do teste de nivelamento TOEFL ITP, o atual nível de proficiência em língua inglesa da comunidade acadêmica (docentes e discentes) da UEPG. Ainda do ponto de vista pedagógico, as experiências no desenvolvimento do projeto, até o momento, também foram muito importantes, levando-se em consideração a necessidade de refletir sobre elas e de refazer os planejamentos inicialmente propostos em conjunto pelas IES participantes do projeto. Nesse contexto, visando atender às necessidades específicas da comunidade acadêmica da UEPG, a coordenação pedagógica do PFI na UEPG tomou a iniciativa de reformular o seu projeto (na segunda e terceira etapas), propondo planejamentos diferentes para cada turma (intermediário e pós-intermediário) - sem comprometimento da finalização do projeto no prazo previsto pela SETI. Com isso, algumas turmas do PFI da UEPG terminaram o livro didático adotado em um ano e outras em seis meses. Diante desse fato, na formação das novas turmas, tanto na segunda etapa do projeto quanto na terceira, a coordenação decidiu disponibilizar menos vagas para alunos novos, podendo, assim, dar continuidade aos cursos em andamento que se iniciaram em 2014.

Ainda, visando à coleta de dados para a discussão do projeto, foi aplicado um questionário avaliativo, baseado no modelo apresentado por Moreira (2013), aos candidatos nos cursos, em dezembro de 2014. Nessa avaliação (que segue a escala de Likert ${ }^{4}$ ), os inquiridos responderam perguntas em relação a: 1) habilidades do professor (domínio do conteúdo, uso do livro didático e de recursos instrucionais, relação interpessoal e didático-pedagógica, etc.); 2) características dos alunos (auto avaliação). Nesta auto avaliação, o/a aluno/a revelou, entre outras categorias, se as estratégias utilizadas no curso foram proveitosas para o seu aprendizado, se ele/ela dedicou tempo suficiente às tarefas do curso, se o curso foi importante para sua formação e se indicaria o curso aos colegas.

A avaliação realizada no final do curso, em 2014, mostrou que 90\% dos participantes consideraram que o curso foi importante para a sua formação e que conseguiram compreender e

\footnotetext{
${ }^{4}$ A escala de Likert é um tipo de escala psicométrica usada em pesquisas de opinião. O respondente do questionário responde uma das cinco proposições: concorda totalmente, concorda, sem opinião, discorda, discorda totalmente. (AMARO; PÓVOA; MACEDO, 2005)
} 
aplicar as estratégias propostas pelos instrutores via livro didático. No fim da avaliação, foi oportunizado um espaço para que os participantes dessem sugestões em relação aos cursos propostos. Dentre as sugestões, algumas estavam relacionadas à oferta de novos horários para os cursos. A coordenação pedagógica esclareceu que a oferta de horários estava condicionada à disponibilidade de horários dos instrutores e à inserção dos alunos de acordo com o nível obtido na prova de nivelamento.

Com isso, conclui-se que os cursos foram proveitosos, tendo em vista a avaliação positiva dos participantes, tanto na modalidade presencial quanto na modalidade à distância.

\section{CONSIDERAÇÕES FINAIS}

A internacionalização do ensino superior deve ser pensada de forma crítica, não como um produto autossuficiente a ser alcançado, mas como um processo social, econômico, político e culturalmente situado (CHAN; DIMMOCK, 2008). Políticas claras e articuladas de incentivo à internacionalização devem ser instituídas no sentido de ampliar os horizontes dos acadêmicos do ensino superior, desenvolver a língua estrangeira e promover o intercâmbio cultural.

O projeto Paraná Fala Inglês, uma das primeiras ações do programa O Paraná Fala Linguas Estrangeiras, com o apoio da SETI e financiado pelo Fundo Paraná, visa elevar o Estado do Paraná, através da harmonização conjunta de ações entre as suas universidades estaduais, ao patamar da internacionalização requerida atualmente no contexto mundial.

O projeto na UEPG tem conseguido atingir seus objetivos, quais sejam: 1) aplicar testes de nivelamento TOEFL ITP; 2) ofertar os cursos preparatórios (intermediário e pósintermediário) do TOEFL iBT; e 3) capacitar alunos (graduação, mestrado e doutorado), docentes e agentes universitários para realizarem o TOEFL iBT. O projeto está sendo um primeiro passo para o processo de internacionalização da universidade, visto que possibilita aos candidatos o desenvolvimento das habilidades linguístico-comunicativas na língua inglesa para que possam fazer o teste do TOEFL iBT e almejar o ingresso em universidades estrangeiras.

A proposta do PFI na UEPG, já concluída em sua primeira etapa, é de extrema relevância, tendo em vista que, pelo grande número de inscritos nos editais, há uma demanda enorme de acadêmicos, pós-graduandos, docentes (em processo de formação em cursos de pósgraduação) e funcionários que necessitam do teste do TOEFL iBT para ingressar em instituições estrangeiras. O projeto tem também promovido a capacitação, em caráter emergencial e de forma 
"Paraná fala inglês" na UEPG: experiência extensionista com foco na mobilidade internacional

pioneira na universidade, de alunos e professores que visam participar do programa federal Ciência sem Fronteiras e de outros programas de internacionalização.

\section{AGRADECIMENTOS}

Agradecemos à professora Ms. Dilma Heloisa Santos pela contribuição na tradução do resumo em Espanhol.

\section{REFERÊNCIAS}

AMARO, A.; PÓVOA, A.; MACEDO, L. A arte de fazer questionários. Porto, Portugal: Faculdade de Ciências da Universidade do Porto. Portugal, 2005.

BRANDERBURG, U.; DE WIT, H. The end of internationalization. In: International Higher Education, n. 62, p. 15-17. Center for International Higher Education, Boston College, 2011. Disponível em: https://www.bc.edu/research/cihe/ihe/issues/2011.html. Acesso em: 5 ago. 2015.

CHAN, W. W. Y; DIMMOCK, C. The internationalization of universities: Globalist, internationalist and translocalist models. In: Journal of Research in International Education. v. 7, n.2, pp. 184204, 2008.

CONSELHO DA EUROPA. Quadro Europeu Comum de Referência para as Línguas: aprendizagem, ensino e avaliação. Tradução de Maria Joana P. do Rosário e Nuno V. Soares. Porto, Portugal: Edições ASA, 2001. Disponível em <http://www.culturaitalianajoinville.com.br/qcerl.pdf>. Acesso em: 5 ago. 2015.

MOREIRA, M. A. Avaliação do professor pelo aluno como instrumento de melhoria do ensino universitário. In: Educação e Seleção, n. 4, p.109-124, 2013. Disponível em: < http://www.fcc.org.br/pesquisa/publicacoes/es/artigos/38.pdf> $>$. Acesso em: 5 ago. 2015.

NOGUEIRA, M. A. Cosmopolitismo científico e escolarização dos filhos: o caso das famílias de ex-bolsistas no exterior. Belo Horizonte, 2006. 100f. (Relatório final de pesquisa $\mathrm{CNPq}$.

NOGUEIRA, M. A.; AGUIAR, A. M. S.; RAMOS, V. C. C. Fronteiras desafiadas: a internacionalização das experiências escolares. In: Educação e Sociedade, Campinas, v. 29, 
“Paraná fala inglês" na UEPG: experiência extensionista com foco na mobilidade internacional

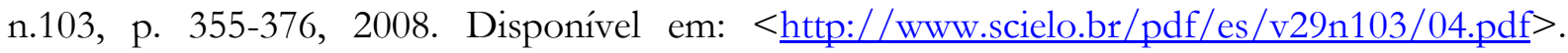
Acesso em: 5 ago. 2015.

PARANÁ FALA INGLÊS. O Paraná Fala Línguas Estrangeiras - Primeira Etapa - O Paraná Fala Inglês - UEPG. Projeto estratégico da SETI - Fundo Paraná. Unidade Gestora do Fundo Paraná - UGF. Secretaria da Ciência, Tecnologia e Ensino Superior, Paraná, 2013.

PHILLIPS, D. Longman Introductory Course for the TOEFL Test iBT. New York: Longman Pearson Education, 2009.

Longman preparation for the TOEFL Test iBT. New York: Longman Pearson Education, 2013.

RAMOS, V. C. C. Perfil e motivações dos estudantes participantes do "Programa de mobilidade internacional para a graduação" da UFMG. 2009. 137f. Dissertação de mestrado do programa de Pós-Graduação em Educação - Universidade Federal de Minas Gerais, Belo Horizonte, 2009.

SCIENCE WITHOUT BORDERS: The Brazilian scientific mobility program at CNPQ/ MCT. June, 2011. Disponível em: <http://www.access4.eu/ media/2011 science without borders.pdf > . Acesso em: 5 ago. 2015.

SCORTEGAGNA, B. A implementação do programa inglês sem fronteiras na Universidade Federal do Rio Grande do Sul. Monografia Licenciatura em Letras Universidade Federal do Rio Grande do Sul - RS, 2013. 